\title{
ON BACKWARD ALUTHGE ITERATES OF HYPONORMAL OPERATORS
}

\author{
Eungil Ko And MeE-Jung LeE
}

Abstract. In this paper we study several remarkable properties of the backward Aluthge iterates of a hyponormal operator. In particular, we show that, under suitable conditions, operators in $B A I H(k)$ admit a moment sequence and have nontrivial hyperinvariant subspaces.

Mathematics subject classification (2010): 47B20, 47A10.

Keywords and phrases: Backward Aluthge iterate, invariant subspace, hyponormal operator.

\section{REFERENCES}

[1] P. AiEnA, Fredholm and local spectral theory with applications to multipliers, Kluwer Academic Pub., 2004.

[2] A. Aluthge, On p-hyponormal operators for $0<p<1$, Inter. Equ. Oper. Theory 13 (1990), $307-$ 315.

[3] A. Aluthge And D. WANG, w-hyponormal operators, Inter. Equ. Oper. Theory 36 (2000), 1-10.

[4] T. ANDo, Operators with a norm condition, Acta Sci. Math. 33 (1972), 169-178.

[5] S. I. ANSARI, Hypercyclic and cyclic vectors, J. Funct. Anal. 128 (1995), 374-383.

[6] S. BRown, Hyponormal operators with thick spectrum have invariant subspaces, Ann. of Math. 125 (1987), 93-103.

[7] S. L. CAmpBell, Linear operators for which $T^{*} T$ and $T T^{*}$ commute, Proc. Amer. Math. Soc. 34 (1972), 409-417.

[8] B. Chevreau, W. Li And C. Pearcy, A new Lomonosov lemma, J. Operator Theory, 40 (1998), $177-180$.

[9] B. Chevreau, I. B. Jung, E. Ko, And C. Pearcy, Operators that admit a moment sequence, II, Proc. Amer. Math. Soc. 135, (2006), 1763-1767.

[10] S. V. DJORDJEVIĆ AND D. S. DJORDJEVIĆ, Weyl's theorems: continuity of the spectrum and quasihyponormal operators, Acta Sci. Math. (Szeged) 64 (1998), 259-69.

[11] K. Dy Kema AND H. SChultz, Brown measure and iterates of the Aluthge transform for some operators arising from measurable actions, Trans. Amer. Math. Soc. 361 (2009), 6583-6593.

[12] C. FoiAs, I. B. Jung, E. Ko, AND C. PEARCY, Operators that admit a moment sequence, Israel J. Math. 145, (2005), 83-91.

[13] T. FURUTA, Invitation to linear operators, Taylor and Francis, 2001.

[14] M. Hladnik and M. Omlacič, Spectrum of the product of operators, Proc. Amer. Math. Soc. 102 (1988), 300-302.

[15] M. Ito, T. YAmaZAKI AND M. YAnagida, On the polar decomposition of the product of two operators and its applications, Inter. Equ. Oper. Theory 49 (2004), 461-471.

[16] I. B. Jung, E. Ko, AND C. PeARCY, Aluthge transforms of operators, Inter. Equ. Oper. Theory 37 (2000), 449-456.

[17] I. B. Jung, E. Ko, AND C. Pearcy, Some nonhypertransitive operators, Pacific J. Math. 220 (2005), 329-340.

[18] I. B. JUnG, E. Ko, AND C. PEARCY, Every operator almost commutes with a compact operator, Kyungpook Math. J. 47 (2007), 221-226.

[19] M. Kim AND E. Ko, Some connections between an operator and its Aluthge transform, Glasgow Math. J. 47 (2005), 167-175.

[20] C. KITAI, Invariant closed sets for linear operators, Ph. D. Thesis, Univ. of Toronto, 1982. 
[21] E. Ko, Backward aluthge iterates of a hyponormal operator have scalar extensions, Inter. Equ. Oper. Theory 57 (2007), 567-582.

[22] K. B. Laursen And M. M. Neumann, Introduction to Local spectral theory, London Math. Soc. Monograghs New Series. Claredon Press, Oxford, 2000.

[23] V. MataChe, Operator equations and invariant subspaces, Matematiche (Catania) 49 (1994), 143147.

[24] C. R. Putnam, An inequality for the Area of hyponormal spectra, Math. Z. 116 (1970), 323-330.

[25] H. RadjaVi AND P. Rosenthal, Invariant subspaces, Springer-Verlag, 1973.

[26] J. G. STAMPFLI, A local spectral theory for operators. V: spectral subspaces for hyponormal operators, Trans. Amer. Math. Soc. 217 (1976), 285-296.

[27] K. TANahashi, On log hyponormal operators, Inter. Equ. Oper. Theory 34 (1999), 364-372.

[28] D. XIA, Spectral theory of hyponormal operators, Op. Th.:Adv. Appl. 10, Birkhäuser Verlag, Boston, 1983. 